\section{FRI0117 INCIDENCE RATE OF HERPES ZOSTER IN RHEUMATOID ARTHRITIS PATIENTS UNDER TOFACITINIB: REAL-LIFE DATA FROM TURKEY - HURBIO REGISTRY}

E. Bilgin ${ }^{1}$, F. Ceylan ${ }^{2}$, E. Duran ${ }^{1}$, E. C. Bolek ${ }^{1}$, B. Farisoğulları ${ }^{1}$, G. K. Yardımcı ${ }^{1}$, L. Kılıç ${ }^{1}$, A. Akdoğan ${ }^{1}$, O. Karadag ${ }^{1}$, Ş. A. Bilgen ${ }^{1}$, S. Kiraz ${ }^{1}$, A. I. Ertenli', U. Kalyoncu'. ${ }^{1}$ Hacettepe Üniversitesi Tıp Fakültesi, Internal Medicine, Rheumatology, Ankara, Turkey; ${ }^{2}$ Hacettepe Üniversitesi Tıp Fakültesi, Internal Medicine, Ankara, Turkey

Background: Tofacitinib (TOF) is an orally administered Janus Kinase (JAK) inhibitor and is commonly used in rheumatoid arthritis. There is a heterogeneity among numbers reported from different continents about herpes zoster $(\mathrm{HZ})$ incidence rate (1-3). However, data about $\mathrm{HZ}$ risk in our country, which stands like a bridge between Asia and Europe, is lacking.

Objectives: To assess the real-life incidence of herpes zoster in RA patients under tofacitinib.

Methods: We analyzed all patients who had at least 1 control visit under tofacitinib and registered to HURBIO database. We calculated incidence rate by dividing the number of patients with herpes zoster to total follow-up years, then multiplied by 100 (per 100 patient-years).

Results: A total of 204 (174 (85.4\%) female) patients were recruited. Mean age was $53.2 \pm 12.5$ years. Mean disease duration was $11.5 \pm 8.1$ years. Rheumatoid factor and anti-CCP antibodies were positive in 135/198 (68.1\%) and $115 / 171(67.2 \%)$ patients, respectively. Median follow-up while receiving TOF was 11.6 (IQR:5.2-26.2) months. Combination with DMARDs was used in $83.3 \%$ of patients. $55.5 \%$ of patients was biologic-naive. Eleven $(5.3 \%$, incidence rate: $3.9(2.3-8.5 ; \% 95 \mathrm{Cl})$ per 100 patient-years) patients had zona zoster. Ten of these patients was female, median age was 59 (IQR; 52-69) and 4 of them was older than 65 years-old. Rheumatoid factor was positive in 9 patients. Only 1 of these patients had diabetes. Median follow-up of these patients under TOF was 8.1(IQR: 6-25) months. Ten of these patients had concomitant DMARDs (9 hydroxycholoroquine, 4 methotrexate, 2 leflunomide; according to last follow-up visit) and 9 of them received concomitant steroids (med(IQR); 4 (1-8) mg- at equivalant methyl-prednisolon dose). Eight of them was biologic-naive. Tofacitinib was discontinued in 4 of these patients.

Conclusion: In this real-life data from Turkey, we found a $\mathrm{HZ}$ incidence rate similar to that reported from USA and global data; however, we found a lower incidence rate that reported from Japan (Figure 1).

\section{$\mathrm{HZ}$ incidence rates (per 100 patient-years)}

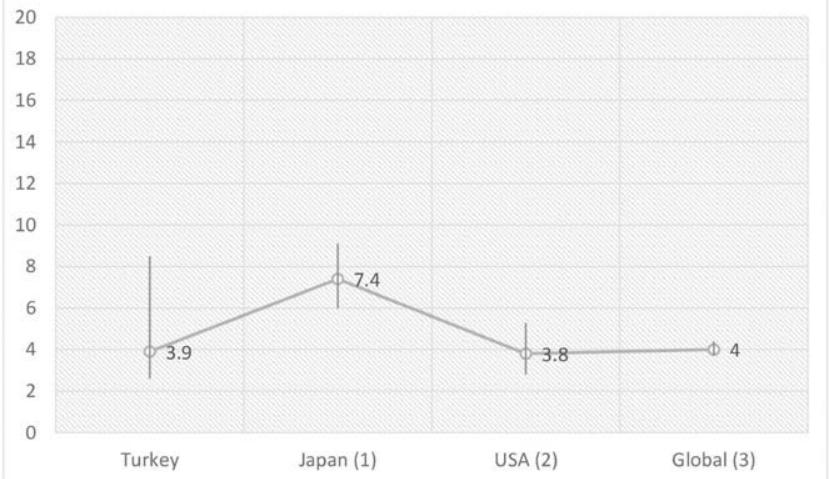

Figure 1. Reported herpes zoster incidence rates across different countries (numbers in paranthesis indicate reference number)

\section{References:}

[1] Winthrop KL, Curtis JR, Lindsey S, Tanaka Y, Yamaoka K, Valdez H, et al. Herpes Zoster and Tofacitinib: Clinical Outcomes and the Risk of Concomitant Therapy. Arthritis \& rheumatology (Hoboken, NJ). 2017;69(10): 1960-8.

[2] Curtis JR, Xie F, Yun H, Bernatsky S, Winthrop KL. Real-world comparative risks of herpes virus infections in tofacitinib and biologic-treated patients with rheumatoid arthritis. Ann Rheum Dis. 2016;75(10):1843-7.

[3] Yamanaka H, Tanaka Y, Takeuchi T, Sugiyama N, Yuasa H, Toyoizumi $\mathrm{S}$, et al. Tofacitinib, an oral Janus kinase inhibitor, as monotherapy or with background methotrexate, in Japanese patients with rheumatoid arthritis: an open-label, long-term extension study. Arthritis Res Ther. 2016;18:34

Disclosure of Interests: Emre Bilgin: None declared, Furkan Ceylan: None declared, Emine Duran: None declared, Ertugrul Cagri Bolek: None declared, Bayram Farisoğulları: None declared, Gözde Kübra Yardımcı: None declared Levent Kılıç: None declared, Ali Akdoğan: None declared, Omer Karadag: None declared, Şule Apraş Bilgen: None declared, Sedat Kiraz: None declared, Al Insan Ertenli: None declared, Umut Kalyoncu Consultant of: Abbvie, Amgen, Janssen, Lilly, Novartis, UCB

DOI: 10.1136/annrheumdis-2020-eular.518

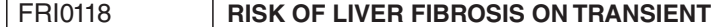 ELASTOGRAPHY IN PATIENTS WITH RHEUMATIC DISEASE UNDER LONG-TERM METHOTREXATE TREATMENT
}

S. J. Choi ${ }^{1}$, J. S. Lee ${ }^{1}$, S. H. Nam ${ }^{1}$, W. J. Seo ${ }^{2}$, J. S. Oh ${ }^{3}$, S. Hong ${ }^{1}$, Y. G. Kim ${ }^{1}$, C. K. Lee ${ }^{1}$, B. Yoo ${ }^{1}$. 'University of Ulsan College of Medicine, Asan Medical Center, Division of Rheumatology, Department of Internal Medicine, Seoul, Korea, Rep. of (South Korea); ${ }^{2}$ Seoul Veterans Hospital, Division of Rheumatology, Department of Internal Medicine, Seoul, Korea, Rep. of (South Korea); ${ }^{3}$ Asan Medical Center, Department of Biomedical Informatics, Seoul, Korea, Rep. of (South Korea)

Background: Methotrexate (MTX) is a cornerstone drug for the treatment of rheumatic disease and low doses of MTX are both tolerable and safe, with monitored toxicity, assessed via the liver function test. However, there is still controversy regarding the risk of liver fibrosis with long-term use of MTX. Transient elastography is commonly used to assess and monitor fibrosis progression in patients with chronic liver disease.

Objectives: The present study aims to investigate liver fibrosis using transient elastography and related factors in patients with rheumatic disease receiving long-term MTX.

Methods: The present retrospective, longitudinal, cross-sectional study included patients with an autoimmune disease who are taking cumulative MTX dosed over $7 \mathrm{~g}$, and who had liver fibrosis upon examination using transient elastog raphy. Liver fibrosis was defined as liver stiffness, valued over $7.2 \mathrm{kPa}$. Logistic regression analysis was performed to identify factors associated with liver fibrosis, and receiver operating characteristics analysis was used to determine the predictive value of each factor.

Results: We included 83 patients with autoimmune disease, with a median MTX cumulative dose of 11.6 (range $7.3-16.0) \mathrm{g}$. Sixty-eight patients $(81.9 \%)$ had rheumatoid arthritis (RA), and 13 patients $(15.7 \%$ ) had Takayasu arteritis. The median MTX exposure duration was 18 (range 9-31) years. The median liver stiffness value was 4 (range 1.8-10.2) $\mathrm{kPa}$. Five patients $(6 \%)$ showed liver fibrosis ( 3 patients; RA, 2 patients; Takayasu arteritis). In the linear regression analysis, cumulative MTX dose showed a tendency towards a positive correlation with increasing liver stiffness value ( $r 2=0.039, p=0.074$ ) In the logistic regression analysis, cumulative MTX dose was associated with a higher risk of liver fibrosis (OR: 1.734, 95\% Cl: 1.060-2.837, p = 0.029). In addition, cumulative MTX dose had an area under the curve (AUC) of 0.813 $(95 \% \mathrm{Cl} 0.695-0.930)$ and a sensitivity of $80 \%$ and specificity of $71.8 \%$ at a cut-off value of $12.7 \mathrm{~g}$.

Conclusion: Liver fibrosis was observed in $6 \%$ of patients with long-term MTX use and higher cumulative MTX doses increased the risk of liver fibrosis. Thus, transient elastography should be considered in patients exposed to high cumulative doses of MTX.

Disclosure of Interests: None declared

DOI: 10.1136/annrheumdis-2020-eular.3553

\section{FRI0119}

C. Codreanu ${ }^{1}$, C. Mogosan ${ }^{1}$, D. Predeteanu ${ }^{2}$, S. Rednic ${ }^{3}$, M. Parvu ${ }^{4}$, E. Rezus ${ }^{5}$, R. Ionescu ${ }^{2}$ on behalf of Romanian Registry of Rheumatic Diseases. ${ }^{1}$ Clinical Center of Rheumatic Diseases "Dr. Ion Stoia", Rheumatology, Bucharest, Romania; "Sfanta Maria" Hospital, Department of Internal Medicine and Rheumatology, Bucharest, Romania; ${ }^{3}$ County Emergency Hospital, Department of Rheumatology, Cluj Napoca, Romania: ${ }^{4}$ Clinical Hospital "Colentina", Department of Rheumatology, Bucharest, Romania; ${ }^{5}$ Clinical Rehabilitation Hospital, Department of Rheumatology, lasi, Romania

Background: JAK inhibitors are the newest therapeutic class available in Romania for the treatment of rheumatoid arthritis (RA). Both available JAK inhibitors (baricitinib and tofacitinib) are fully reimbursed.

Objectives: Efficacy and safety data for JAK inhibitors, derived from the Romanian Registry of Rheumatic Diseases (RRBR). 